SHORT REPORT

\title{
Handheld computers in medicine: the way forward
}

\author{
A Horsley, L Forster
}

Postgrad Med J 2005;81:481-482. doi: 10.1136/pgmi.2004.029793

Handheld computers are now a common sight in medicine, but there are scarce data on who actually uses them and what functions are found to be most useful. This is the first study of handheld computer use in a British hospital, and shows that there is already considerable use and acceptance of the technology, with 22 of $55(40 \%)$ physicians possessing and using such a device. Doctors in training grades are more likely to make use of medical software, particularly textbooks, calculators, and formularies. The main barriers to greater use of this technology were cost of software and poor applicability to UK practice.

$\mathrm{U}$ se of handheld computers by medical staff is becoming increasingly common on the wards. Highly capable pocket computers can now be purchased for as little as $£ 100$, about one third of the price of the much more basic entry level devices of three years ago. Escalating sophistication and memory means that these devices are now very much pocket computers rather than just digital diaries, and can be used to store and retrieve large amounts of information. This includes Word documents, email, and Excel spreadsheets. There is also a burgeoning market for medical software, including practice guidelines, textbooks, and formularies.

The aim of this study was to describe the use of handheld computers on UK medical wards, both in terms of who is using them, and what they use them for. We also aimed to describe some of the barriers that owners had experienced in trying to use medical applications.

Data from the USA suggest that two thirds of medical students now own and use personal digital assistants (PDAs) for clinical work. ${ }^{1}$ This survey provides the first data on the use of such devices in UK hospitals.

\section{METHODS}

A questionnaire was distributed over the course of a week to all the medical staff involved in acute medical admissions at a medium sized district general hospital in North Yorkshire ( 718 beds). Inclusion criteria were all grades of medical staff from all acute medical specialties in the hospital. We excluded those only involved in subspecialties and without responsibility for acute medical takes as it was felt that those involved with acute admissions would have more use for different medical software applications, for instance those dealing with topics outside of their primary specialty.

Respondents were asked whether they possessed a PDA, and if so they were asked to estimate how often they used it and what it was used for. Those who did not possess a PDA were asked whether they intended to purchase one and reasons for not doing so. The replies largely consisted of a number of tick box responses, developed after discussion with other PDA users and field tested before distribution. There were also a number of open questions with space for respondents to enlarge on problems that they had experienced while using medical software. The questionnaires were not anonymous.

\section{RESULTS}

From a total of 62 physicians eligible for inclusion, questionnaires were collected from 55 (89\%) across a range of primary specialties and grades.

Twenty two (40\%) of these possessed a PDA. Most of these (15) used systems based on Palm software.

\section{Demographics of PDA use}

PDA users came from all specialties. There was greater ownership among specialist registrars $(7$ of 11$)$ and consultants (9 of 19) (fig 1). Interestingly, although 14 $(25 \%)$ of the staff questioned were female, all but one of the PDA owners were male.

\section{Nature of PDA use}

Fifteen $(68 \%)$ of respondents used their PDAs three or more times per day, and three used them more than 10 times per day. The most popular applications were the standard PDA functions of address book, diary, memo pad, and calculator, but $11(50 \%)$ also used their PDAs for medical applications (table 1).

The most popular medical software was drug formularies (used by 3 of 11 of those who used their PDAs for medical applications), textbooks (used by 5 of 11), and medical calculators (used by 7 of 11). The only formulary used was ePocrates Rx (http://www.epocrates.com), an American freeware application. ${ }^{2}$ There were three users of the PDA version of the Oxford Handbook of Clinical Medicine (http:// www.franklin.com), and two users of the 5 Minute Clinical Consult textbook (http://www.skyscape.com). Medical software was only used by two consultants (the remaining seven only used their devices for the standard PDA functions) but by five of seven specialist registrars and by all four senior house officers.

Respondents were asked what problems they had experienced with medical software for handheld computers. Nine

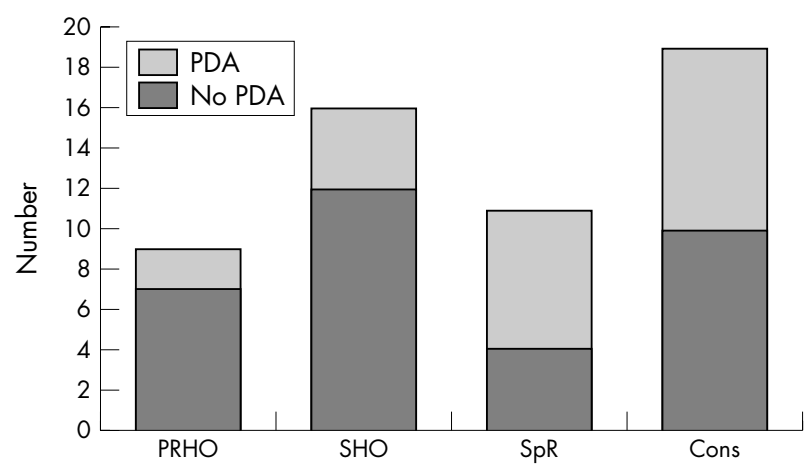

Figure 1 Handheld computer ownership by grade of physician. PDA, personal digital assistant; $\mathrm{PRHO}$, pre-registration house officer; $\mathrm{SHO}$, senior house officer; SpR, speciálist registrar; Cons, consultant. 


\begin{tabular}{ll} 
Table 1 & Nature of handheld computer use \\
\hline Function & Number of users (\%) \\
\hline Address book & $15(68)$ \\
Diary & $17(77)$ \\
Notepad & $11(50)$ \\
Medical software & $11(50)$ \\
Calculator & $11(50)$ \\
Word & $6(27)$ \\
Spreadsheet & $7(32)$ \\
Games & $6(27)$ \\
Internet/web pages & $4(18)$ \\
Email & $4(18)$ \\
MP3 (music) & $2(9)$ \\
\hline
\end{tabular}

subjects completed this section of the questionnaire, all replied that cost was a factor and six indicated that the bias of software for US practice was a problem.

Subjects were asked to indicate what software they would like to see available for use. Five wrote that they wanted to be able to use the British National Formulary on their PDA and another five that they wished to see more UK oriented clinical guidelines made available. Four indicated that they would like to be able to access hospital pathology results from their handheld computers.

\section{Future PDA use}

Those physicians who did not possess a PDA were asked whether they had plans to purchase one. Of the 32 respondents to this section, seven $(22 \%)$ replied that they planned to buy one within the next year, 17 (53\%) indicated that they might do so in the future, and six (19\%) replied that they would never purchase one. Most gave the reason that they had no need of such a device.

\section{DISCUSSION}

This was a limited study, designed to provide insight into the current uptake and use of handheld computers in the UK, and to investigate some of the problems experienced with medical applications. Only physicians involved in acute medicine in one hospital were surveyed so caution must be used in extrapolating these findings to different branches of medicine or to different regions. However, there is no reason to suppose that the increasing use of handheld computers is a purely local phenomenon, and the experiences of users are likely to be broadly similar throughout the UK.

Half of owners used medical software on their devices but these tended to be the more junior physicians. Studies conducted with junior hospital doctors have shown that PDAs permit rapid and convenient retrieval of medical information, drug dosing, and commonly used formulas, ${ }^{2-5}$ reflecting the types of software used by users in this study. However, there was comparatively little uptake of such software, with most using less than two different applications. PDAs are also helpful in training as a means of recording logs of patients seen and procedures performed, ${ }^{6-8}$ although no owners reported such activities. There was a reluctance to pay for software, and all respondents to this section identified cost as an issue. Clearly there are further questions to be answered in this area. In particular it is not clear what costs users would be prepared to pay to have the software that they identified a need for. This is an issue likely to be faced by commercial developers rather than organisations that produce management guidelines as freeware.

A recent qualitative study on US physicians ${ }^{5}$ described much greater use of PDAs (83\% of the sample owned and used such a device), but the authors had selectively sampled from institutions known to be using handhelds in clinical practice. Furthermore, the respondents were self selected, and no response rate is given. However, although this study is not directly comparable to ours, the two are complementary. McAleareney et $a l^{5}$ divided handheld owners into three categories based upon their use of the device: niche users, regular users, and power users. Similar proportions of users in each category are found in our data, with the niche users tending to be at more senior grades (and using their PDAs as organisers) and the more enthusiastic users, who also use them to access medical software, being those in training grades. Although we could not go into the same depth that McAleareney et al were able to do, we did identify that users felt that there was a lack of good quality medical software for them to use. In particular users complained that software was often designed around US practice, and not always applicable. Even those who regularly used ePocrates indicated that they would prefer to use the British National Formulary instead if cost was not an issue. Unlike the US study, this seemed to be the main barrier to greater use of medical applications, and there were no complaints about the devices themselves or concerns about excessive dependency. This may reflect the small numbers of "power users" in the UK, those who are likely to push their device to its limits.

It is clear that handheld computers are becoming increasingly prevalent in medicine. Whereas three years ago these devices were regarded as a rare novelty, they are now used by $40 \%$ of hospital physicians in general medicine in this survey. Over half of all respondents either possessed a device or planned to buy one in the next year, although this remains far below the reported and projected use of such devices in the USA. ${ }^{39}{ }^{10}$ There is still considerable unused potential, even among the enthusiastic adopters of this technology, which may increase with better and more appropriate medical software.

\section{Authors' affiliations}

A Horsley, Department of Respiratory Medicine, York District Hospital, York, UK

L Forster, Department of Medical Oncology, St James's University Hospital, Leeds, UK

Conflicts of interest: none declared.

Correspondence to: Dr A Horsley, Department of Respiratory Medicine, York District Hospital, York YO31 8HE, UK; alex.horsley@tiscali.co.uk

Submitted 16 October 2004

Accepted 23 November 2004

\section{REFERENCES}

1 Brock DM, Scott T, Wick KH. Student use of handheld computers in clinical settings: a survey. Perspect Physician Assist Educ 2003;14:12-15.

2 Rothschild JM, Lee TH, Bae T, et al. Clinician use of a palmtop drug reference guide. J Am Med Inform Assoc 2002;9:223-9.

3 Beasley BW. Utility of palmtop computers in a residency programme: a pilot study. South Med J 2002;95:207-11.

4 Lapinsky SE, Weshler J, Varkul M, et al. Handheld computers as a reference source in the ICU. Am J Respir Crit Care Med 2001;163:A258.

5 McAlearney AS, Scweikhart SB, Medow MA. Doctors experience with handheld computers in clinical practice: qualitative study. BMJ 2004;328: $1162-6$.

6 Hammond EJ, Sweeney BP. Electronic data collection by trainee anaesthetists using palm top computers. Eur J Anaesthesiol 2000;17:91-8.

7 Bird SB, Zarum RS, Ranzi FP. Emergency medicine resident patient care documentation using a hand-held computerized device. Acad Emerg Med 2001;8:1200-3.

8 Nicolau DD, Davis GL. A distributed asynchronous resident procedure log for hand-held devices. Acad Emerg Med 2001;8:583.

9 Ebell MH, Gaspar DL, Khurana S. Family physicians preference for computerized decision-support hardware and software. J Fam Pract 1997:45:127-8.

10 Criswell DF, Parchman ML. Handheld computer use in US family practice residency programmes. J Am Med Inform Assoc 2002;9:80-6. 